\title{
THE ORGANISATION OF FRACTURE CLINICS IN EUROPE AND AMERICA.
}

\author{
By H. E. GRIFFITHS, M.S.(Lond.), F.R.C.S.(Eng.). \\ (Surgeon to the Albert Dock and Hertford County Hospital, Consulting Surgeon to \\ Wimbledon Hospital, etc.)
}

The need for Fracture Clinics is universally acknowledged, but there is considerable difference of opinion as to what type of clinic should be established. There can be no doubt that the treatment of fractures is a branch of surgery that has lagged sadly behind in the general progress that has marked the last fifty years. It might be supposed that the treatment of fractures in the hands of the acknowledged expert should show a quite remarkable lessening of the period of incapacity for work that follows industrial injuries but, surprisingly and unfortunately, the figures are not borne out entirely by an impartial scrutiny of very large numbers of cases. The figures published in the British Medical Association fracture report were certainly impressive but they will not bear the careful scrutiny of the actuary, who must have exactly parallel cases for comparison.

There must be something radically wrong in the general conception of the treatment of fractures if figures do not show a very material reduction in the period of incapacity in cases in the hands of the fracture specialist. If we are to take certain special cases such as fracture of the neck of the femur the value of the fracture specialist's work is seen at once but certain other cases tend to belittle it. For example, in crush fractures of the body of a vertebra it is probable that the majority of these cases, possibly as high as 90 per cent. of them, are never diagnosed and return to work within a few weeks of their injury, having been treated for strained back.

It is possible that the surgeon confronted with a recent fracture adopts the wrong viewpoint. He wishes to restore the limb as far as possible to the status quo ante and anatomical considerations will be uppermost in his mind. If the patient is consulted he will probably say that the dearest wish of his heart is to get back to work and that at the earliest possible moment. In the case of the workman he must have strong limbs and supple muscles. The actual form of the limb does not matter much so long as he has the necessary strength and sufficient movement to perform his daily task. It is to be feared that in modern methods of treatment mobility has been sacrificed to symmetry. If the surgeon's first consideration were getting the patient back to work quickly I think we should make rapid progress in our treatment of fractures. He must study the case, then, from the physiological rather than from the anatomical standpoint. In order to do this properly he must know something about the work that the man has to do and the disabilities which may follow his fracture and incapacitate him for this work.

If one considers fracture treatment outside the British Isles possibly two of the most successful clinics are those of Böhler in Vienna and of O'Neill Sherman in Pittsburgh, but their initial treatment is fundamentally different. Böhler aims at immediate reduction of the fracture and then immobilisation of the part in plaster of Paris in such a way that the limb as a whole can be constantly exercised. Sherman does an open operation, plating the fractured bone, and then starts treatment on the muscles immediately; massage and faradism and active movements are 
commenced on the day after the operation. In both schools, therefore, the setting of the fracture is only incidental to the treatment of the muscles and joints by activ exercises. But although both men are artists in their methods of initial treatment this is not the primary reason why their results are outstanding. Other men may equal them in technique but few, if any, have the opportunities of continuing the treatment as they do. Böhler, dealing with a nation accustomed to drill an\& obedience, instructs his men in exercises which they feel compelled to carry out an although he has an inspiring personality and the men have the utmost faith in him he is able to control them as a military officer does his men. Sherman's technique is entirely different and equally effective. $\mathrm{He}$ is the head of the medical service of the Carnegie Illinois Steel Trust. $\mathrm{He}$ is a most inspiring personality and is trusted and worshipped by his patients, with whom he always appears to be on the most friendly terms, but he has two enormous advantages. First, that the men heg treats are kept on their full wage during their period of incapacity, and secondly. that as soon as he thinks they are fit to do any form of work, either useful or com! passionate, he is able to find them the ideal job. In this respect he has dictatoriat powers, being able to ring up the mills, the lumber camp, etc. and name the job he wishes the man to do. This job has to be found.

Of the very many fracture hospitals and clinics that I have visited in Europe and America O'Neill Sherman's results are the most nearly perfect and in mo view his outstanding success is due mainly to this ability always to place the injured man in suitable work.

Unfortunately, in recent years a great deal of confusion of thought has arisent through the meaningless repetition of words like "Rehabilitation" and "Af(gefe Care " in speaking of the treatment of fractures. It might be supposed that treatment of fractures should be divided into two distinct and entirely separate stages, first, the treatment by surgeons in hospitals and then, when the surgeop had finished, the treatment by teachers in vocational training shops.

Rehabilitation is a word which came into common use during the latter part of the Great War. It was then used to define the efforts made by various bodies? mostly charities, to train permanently crippled and disabled men to help to support themselves. As examples in this country we had the work done by St. Dunstan's Lord Roberts' Memorial Shops and the tuberculosis colonies. In America, i Ig00, Dr. E. J. Halms of Boston started the Goodwill Industries. This organisa tion collected gifts of old toys, furniture, clothes, etc., and had these articles repaired by the crippled and disabled. The articles were then sold in the poorer parts of the city and the proceeds enabled the patients to become in part selfe supporting. By I928, Goodwill Industries had been started in fifty-one cities in the United States.

More recently, more comprehensive schemes of rehabilitation centres have bee established in various States but it has been found that with the growth of the scheme the meaning of the word rehabilitation has expanded. For example, in the New Jersey Clinic, a large proportion of the cases seen have been disabled by fractures and of these seventy-six per cent. required further surgical treatmente In fact, rehabilitation as understood by this clinic comprises surgical treatment? physiotherapy and occupational therapy. It must be understood, then, that whereas originally rehabilitation referred to the training of the permanently cripple ${ }^{2}$ it now implies the treatment of the injured. Rehabilitation starts with the arrivat of the ambulance at the scene of the accident and continues until the patient is reo established in industry, earning his pre-accident wage. 
If the principles of rehabilitation in its wider sense are to be properly understood it is necessary to study those end-results of injury which prevent the patient from ultimately resuming full work; and, from the earliest possible moment, so to direct treatment that these " end-result disabilities" shall disappear. For example, the moment a femur is broken the man is incapacitated because the limb loses its power to bear the weight of the body, but in hardly one per cent. of cases is the " end-result disability" failure to bear the weight of the body. On the contrary, it is something like instability of the knee joint or stiffness of muscles, in fact some condition which has arisen during treatment. Rehabilitation consists then first in preventing these disabilities, secondly in relieving them and finally in training round them. I could find no-one in America who had made a study of " end-result disability."

Amongst many hospitals visited in the United States the principles of rehabilitation as described above are generally imperfectly understood or practised. On the other hand, in one or two special hospitals, notably in Dr. O'Neill Sherman's Clinic in Pittsburgh, efforts are directed from the moment of the occurrence of the accident towards refitting the man in industry. It is more than just a group of beds in a hospital. The clinic embraces the whole of the organisation for handling the man from the time of his accident until he is back at work and it is presided over by Dr. O'Neill Sherman with a staff of sixty doctors.

The injured workman receives treatment from the first-aid squad where he lies. If he has a fracture some form of splint is applied. $\mathrm{He}$ is then taken to the casualty surgery in the works and seen by the doctor in attendance. $\mathrm{He}$ is then transported in one of the Company's ambulances to the clinic where he comes under the personal attention of Dr. O'Neill Sherman. Any operative treatment that may be required is carried out at once and physio-therapy, almost confined to the use of a Smart-Bristow coil, is started at once. As soon as the patient is ambulatory he is discharged from the wards but continues to attend the out-patient department, again remaining under the direct supervision of Dr. O'Neill Sherman. Here his treatment in the main is confined to faradism with the Smart-Bristow coil and some form of radiant heat. The gymnasium is sparsely equipped and very little used. Occupational therapy is non-existent but Dr. O'Neill Sherman has the immense advantage of being able to send men back to work on all kinds of compassionate jobs, so that his occupational therapy really takes place in the mills.

The results obtained by Dr. O'Neill Sherman are extraordinarily good and better, I think, than would be found in any individual collection of cases in this country. The factors that to me appeared to account for his success were :-

I. His personality. He was obviously loved and trusted by every patient with whom he came into contact. He inspires hope and courage and each man knows that there is a job waiting for him as soon as Dr. O’Neill Sherman pronounces him fit.

2. Dr. Sherman is himself a surgeon of outstanding ability.

3. He has a perfectly trained team.

4. The patients are well cared for and well-fed during treatment.

5. There are no grounds for the development of anxiety neuroses associated with fear of unemployment or litigation.

In the majority of hospitals visited in the United States the results obtained from the treatment of fractures fall far short of those in the Sherman Clinic. 
In order to understand this comparative failure of treatment it is necessary to analyse the various aspects of the hospital system. Most of the hospitals that care for patients injured in industry are "open." That means that any doctor sending in his patient may look after that patient, even, in most cases, to the extent of operating. The various State compensation laws provide for the payment of the medical expenses of the injured workman, varying from fifty to eight hundred dollars. These laws also provide for maintenance in hospital for a period of twenty-eight days up to six months, with an average of about thirty days. It will be seen then that both the general practitioners and the hospitals have a vested interest in the patient up to a certain period and for that reason there is often considerable opposition to the principle of segregation of fracture cases for treatment in organised fracture clinics. After, however, the funds are exhausted this opposition is not so strong and then in many cases the work of the rehabilitation centre begins. It will be readily appreciated, therefore, why in the New Jersey Centre it has been found that seventy-six per cent. of fractures still require surgical treatment.

Another factor that has a profound bearing upon treatment is what in Britain would be looked upon as the interference of the insurance doctors. These men, usually whole-time employees of the companies, appear to exercise the privilege, not only of examining the patient as they do in this country, but of dictating the 9 treatment. Now it is greatly to the insurance companies' benefit to see that patients are discharged from hospital at the earliest possible moment since up to a certain $\subseteq$ figure they have to bear the cost of hospital maintenance and if there is co-operation $\Phi$ between the insurance doctor and the doctor who has charge of the case methods $\vec{\omega}$ of treatment may be adopted which ensure the patient's becoming ambulatory a an early date but do not always secure the best end-results. As an example, on case I saw was a fracture of the femur. Four Steinmann's pins were drivent through the bone, two pins being above the line of fracture and two below. By means of a Roger Anderson reduction appliance the bones were brought into good position. Plaster of Paris was then applied to the whole of the leg and lower part $\stackrel{\circ}{2}$ of the trunk. The four Steinmann's pins were included in the plaster case, and so $\overrightarrow{\vec{O}}$ maintained the position of the fractured bone, and the patient within a week of 3 his accident was to be discharged to his home. The insurance company represen-? tative was satisfied that in this appliance the man was fit to be moved and that? therefore the company was no longer liable for his maintenance in hospital. Theo man himself was unable to afford to pay for hospital treatment. This type of treatment has certain advantages but it finds no place in Dr. Sherman's 3 clinic because it prevents the early use of massage and faradism, movements of theo joints, i.e., it prevents any early effort at rehabilitation apart from securing union३ of the bone in good alignment.

Yet another way in which the treatment of fractures is influenced by the dictates of the insurance companies is the result of the compensation laws of the states. Compensation is paid for anatomical and physiological disability, whereas in Britain no compensation is paid on these lines but only for loss of earning capacity. Treatment, therefore, in the hospitals now being considered is often? aimed mainly at the restoration of the form of the limb without considering the $e^{\omega}$ use of the limb. Take the case of a woodworking machinist who had sustainede compound fractures of each of the small bones of the right index finger. If union? be obtained with the fragments in good alignment although with bony fixation of the joints so that the whole finger remains stiff and straight, he is entitled to compensation on a basis of something less than total loss of the index finger, although the stiff index finger might get in his way so much when engaged upon a spindle 
machine as to prevent his doing his work. This disability in England would incapacitate him from earning and therefore he would be entitled to his full compensation. On the other hand, if the index finger had been amputated at the time of the injury, in America the man would be entitled to a larger sum of money than if he had a stiff finger whereas in England he would probably not have been entitled to anything as he would be able to do his full work, having no stiff finger to handicap him.

At the Medical Centre in New York a determined effort has been made to deal with the problems of fractures by the establishment of a Fracture Clinic under the direction of Dr. Darrach, who is himself employed part-time but who has under him a complete staff of whole-time officers, his first assistant being Professor Ray Murray and his second Dr. Stimson. In this clinic there are thirty ward beds in addition to private rooms which are available alike for fractures or other surgical conditions. The clinic comprises an out-patient department complete with waiting rooms, examining rooms and plaster rooms and with ready access to the X-ray unit. There is an elaborate X-ray unit which is available not only for fractures but for other medical and surgical conditions, but in addition there is a portable $\mathrm{X}$-ray in relation to the fracture operating suite. The operating suite itself is adequate without being nearly as elaborate as some others we saw. The physiotherapy department is large and well-equipped although the only forms of treatment that appeared to be advocated for fractures were massage, radiant heat and to a lesser extent faradism. The gymnasium and occupational-therapy rooms, although present, were little used. On the other hand, various forms of occupational therapy such as needlework, basket-making, etc., were urged upon the patients whilst they were still confined to bed.

Rehabilitation in this clinic starts at once and most of it is preventive. In the words of Dr. Ray Murray,

"The essential feature of this phase of treatment is active functional use of the part by the patient. Physical therapy is of use here only in so far as it makes such use possible or easier, or in so far as it can deal with the distressing effects of overuse. One of the chief reasons why physical therapy is considered by many to be useless in fracture treatment is because patients are returning two to three times weekly, or oftener, week after week, month after month, to countless clinics and offices in this country, patiently waiting for physical therapy to restore strength and activity to stiff and atrophied limbs. It cannot be done, no matter how efficiently the treatment may be given. The only one who can complete the cure at this stage is the patient. With physical therapy we can make it easier for him, less distressing to him, but the patient himself must do the work. It is absolutely essential that the doctor, the technician and the patient be aware of this fact. And if any one of them thinks, as they too often do, that some form of electrical or other physical force can take the place of the voluntary activity of the patient, physical therapy at this stage becomes not only a waste of time, but a harmful procedure. It is this fact that must be forced into the consciousness of doctor, physical therapist, technician and patient .... In the treatment of fractures, the thing that counts apart from the actual reduction is not what we can do for the patient but what we can help the patient to do for himself."

In Dr. Darrach's Clinic the use of complicated apparatus in the after treatment of patients is discounted, as they say thousands of pieces of apparatus have been designed to cure the patient through the exercise of physical therapy but none of them is capable of obtaining results that cannot be obtained by the use of heat and gentle massage. The effect of the apparatus is more to spare the time and energy of the doctor and may even replace lack of skill and practice on his part; the effect 
it exercises on the psychology of the patient may be either good or bad and at best it can only offer a relatively inefficient substitute for the patient's voluntary muscular activity.

Their views on early rehabilitation of patients have led Dr. Sherman and Dr. Darrach and his colleagues to adopt the open method of treating fractures in the majority of their cases. By this is meant that an operation is performed shortly after admission of the patient to the hospital; the broken bones are brought into alignment and fixed with screws or plates. When this is done treatment of the fracture by extension is unnecessary and it is easier to apply massage and electrical treatment to the limb and to encourage the patient to exercise his joints. In their hands the treatment by operation has proved very successful. Dr. Sherman's records show that he has had only six cases of sepsis in his fractures in over thirty years of treatment. But it cannot be denied that only with very highly-skilled team work can results like this be obtained by open operation. Dr. Darrach himself teaches his students that since they cannot hope to operate in conditions such as he has at the Presbyterian Hospital they should avoid open operation and should treat their patients by other more conservative methods. These methods are not shown at his Clinic and therefore, the medical students who rely upon their experience in that hospital for their training in the treatment of fractures must pass into the world as ill-equipped in this department as the generality of medical practitioners.

When pure surgery has done all it can for the patient there still remain a certain number of cases who are permanently incapacitated from resuming their former occupation. If these people are to be usefully employed they must be trained round their disability. The success of such training depends more upon the man's adaptability than upon his actual injury. At the New Jersey Rehabilitation Centre? they consider that vocational training should be reserved primarily for the young disabled group. Of the cases that are referred for rehabilitation 76 per cent. require and receive further surgical treatment. Of the remaining 24 per cent. only a small proportion are fit for training. It is found that only in the case of the young is it a sound economic proposition to attempt vocational training. The first step is to have the patient examined by a psychologist in an effort to determine what branch of training is likely to benefit him most. He is then examined in the fundamentals of grammar-school education and deficiencies in this are repaired. In some cases they send teachers out to individual bedridden patients' homes. If the patient proves sufficiently adaptable he is then taught some trade within his limits; a one-armed man, for instance, can be trained as an acetylene welder; a one-legged man may learn to operate a machine or be instructed in mechanical drawing, etc. It is found that the hardest man to place in industry is the man with a crutch, and for that reason all patients who have lost a leg are encouraged to wear an artificial limb. An operation to re-fashion the stump is frequently necessary before such an appliance can be fitted.

To recapitulate, rehabilitation methods in the treatment of fractures must start with the arrival of the ambulance, since even a temporary splint improperly applied may result in permanent damage to a limb. The treatment of fractures from the time of injury until the patient resumes work should be under the control of one man. The treatment where possible should be undertaken in a specially designed fracture clinic with a fully trained staff. Operative treatment or manipulative treatment, physio-therapy and occupational therapy should run concurrently rather than successively. Final success depends largely upon the personality and skill of the 
surgeon coupled with the co-operation of the patient and his employer. Above all things the patient must be taught that his cure depends largely upon his own efforts. In fact, getting fit for him is a whole-time job.

To refer back now to the opening paragraph of this article, the probable reason why the specialist's efforts in the treatment of fractures are not crowned by much greater success than is borne out by actuarial figures is due to the fact that he has not the opportunity of employing his patients in work in the latter and more important part of their treatment. As surgeons it has taken us I50 years to live down John Abernethy's famous dictum, "Keep the injured part at rest." Now we must solve the problem of how to "keep the injured part at work." My own slogan which I should like to see universally adopted is "Getting fit is a whole time job." In fact, getting fit is a job of work and like every other form of work it needs a 44-hour week.

The earliest conception of the Fracture Clinic was the collection of cases attending the massage department. These would be told to come up on a specific day, weekly, bi-weekly or monthly when they were all to be examined by the medical officer in charge of the department and their treatment prescribed. This is the commonest form of fracture clinic found in Great Britain and in the United States and, speaking generally, it achieves next to nothing in the improvement of the treatment of fractures.

The second stage in the development of the fracture clinic is the periodic re-examination of the cases by the surgeon who originally dealt with the fracture, even though the patient may now be receiving his treatment in the massage department under the supervision of a different medical officer.

The third stage marks the first step in " unity of control." The patient, both whilst an in-patient and an out-patient, come under the direct and constant supervision of the same surgeon in spite of having his treatment in the massage department, etc. prescribed by another specialist. In this stage the fractures are scattered throughout the wards of the hospital, coming perhaps under the surgeon on duty or perhaps being treated by one, two or more general surgeons or orthopædic surgeons.

The fourth stage marks the complete segregation of fractures within a general hospital. A special ward or portion of a ward is reserved for fracture cases coming under the direct supervision of one man who follows them throughout the whole course of their treatment.

An earnest attempt to solve the question of the treatment of fractures has been made by the Seamen's Hospital Society who are opening in July a model fracture clinic. This clinic is to be complete so that the man is cared for from the moment he meets with his accident until he is fit to return to his full pre-accident work. In Dockland something more is needed than a place for the setting of the fracture and arrangements for the ultimate working of the limb. The patient must also be properly fed. In the out-patient department one of the most potent causes of delayed union of fractures and of prolonged incapacity for work is found to be under nourishment. In the new Fracture Clinic arrangements are made for the out-patients to be fed in the hospital.

The Clinic is housed in an entirely new building. It comprises an ambulance which is always kept heated and has a specially-trained team always waiting to proceed to the site of an accident within the docks, or to meet a ship bringing in an injured man. When the ambulance reaches the hospital it passes straight into 
the building and the patient, in the case of a serious injury, is taken directly into a shock room. This resembles, somewhat, a small theatre, the temperature of which is kept high. The patient, still remaining on the stretcher if necessary, is placed in a radiant heat bath. Within the room ready waiting is the apparatus for saline transfusion or blood transfusion. Thus all the appliances for the treatment of shock are already mobilised in this shock room. Much valuable time is saved and the patient is moved about as little as possible. From the shock room the patient may be transferred direct to the ward or fracture theatre, etc.

On the ground floor also are found an ordinary out-patient department comprising waiting-room, examination rooms, consulting rooms, with an out-patient theatre and also a complete X-ray department. There are also an out-patient dining room and a large gymnasium with locker room and shower baths, etc. But the gymnasium is not equipped with the ordinary type of apparatus. All the exercises prescribed for the men are in the form of games, as far as possible competitive games. This is best illustrated by the rowing machines. The ordinary machine is fixed and it is dull work and can be made very strenuous work. The new rowing machines are mobile. With each complete stroke they progress about I inch, thus enabling the rower to travel from one end of the gymnasium to the other. It is endeavoured to make this form of work interesting by rowing relay races of four a side on two machines, so that those not actually rowing will encourage the working member of the side. Another feature of the machine is that very little effort has to be made to work it, the aim being to achieve rhythm of muscular movement rather than exertion.

Out-patients must report at 8.30 in the morning if they desire to have breakfast, or at 9 if they do not desire it. They will work throughout the whole day at prescribed exercises under the supervision of a trainer, dinner being served at midday in their special dining room. They will thus achieve their 44-hour week at work. In addition to the gymnasium will be an occupational work room for special cases and for men who volunteer for that type of work.

There are, of course, massage and electro-therapeutic departments. There is also a combined record room and lecture room. In the lecture room it is hoped to organise short concerts, etc. for the men.

On the first floor of the building are the wards. The twenty-four bed wards have the beds arranged in four pairs and four groups of four. Each bed can be completely shut off as a cubicle if necessary. At the end of a ward is a large sun and rest room and opening from this a large roof garden. All the doors are wide so that the beds are easily wheeled directly out through the rest room on to the roof garden. A At the other end of the ward is a dressing room which again is equipped like a small theatre. Into the dressing room beds can be wheeled if it is desired to give a patient an anæsthetic in bed or any special dressing, etc.

In addition to the general wards are single rooms where special cases, e.g. fractures of the skull, may be treated if thought necessary. There are an adequate number of electrical points for the portable X-ray or electrical apparatus of other kinds to be brought to each bed.

The theatre block consists of two large theatres, one being reserved entirely for clean bone cases. Both theatres are equipped for the use of $\mathrm{X}$-ray apparatus. In the first theatre the dark room leads directly off the theatre and the film, as soon as it is developed, can be shown through a panel in the wall without being brought back into the theatre. 
Outside the building is a garden sufficiently large for walking exercise and space has been reserved and plans drawn up for the building of a swimming bath when funds are forthcoming.

The personnel consists of an honorary surgical director who will attend on each day, at least during the first year, and who will undertake the care of the fractures throughout the whole of their treatment. There will be a resident surgical officer appointed annually for a period of three years, his salary rising from $£ 300$ to $£ 400$ a year, who must have a fellowship of one of the Royal College of Surgeons. Arrangements have also been made with one of the leading American hospitals for an interchange of internes so that a suitable candidate will be sent for six months or a year to America.

In addition to the resident surgical officer there will be two house surgeons. The X-ray department will be in charge of a consultant radiologist and there will be a resident radiographer. The electro-therapeutic department and the massage department will be in charge of a sister and will come under the direct supervision of the surgical director. There will be a trained medical secretary responsible for the notes and who will also do a certain amount of the almoner's work, keeping in personal contact both with the patients and with their employers, making an effort in every case to secure a promise of remunerative employment when the patient is sufficiently fit to undertake it. The gymnasium, as already indicated, will be in charge of a trainer who must be a man of inspiring personality. He will probably be chosen from the ranks of the professional footballers.

Another important member of the personnel will be the technician. He will be responsible for all the splints, apparatus and plaster used in the hospital. $\mathrm{He}$ is being trained to become expert in the applications of plaster, etc. and in addition to being trained in the present hospital has been sent by the Seamen's Hospital Society to Vienna to study the methods used by Dr. Böhler's technician. 